\title{
A Framework for the Land Use Change Dynamics Model Compatible with RCMs
}

\author{
Xiangzheng Deng, ${ }^{1,2}$ Jiyuan Liu, ${ }^{1}$ Yingzhi Lin, ${ }^{3}$ and Chenchen Shi ${ }^{1,4}$ \\ ${ }^{1}$ Institute of Geographic and Natural Resources Research, Chinese Academy of Sciences, Beijing 100101, China \\ ${ }^{2}$ Center for Chinese Agricultural Policy, Chinese Academy of Sciences, Beijing 100101, China \\ ${ }^{3}$ School of Mathematics and Physics, China University of Geosciences (Wuhan), Wuhan 430074, China \\ ${ }^{4}$ State Key Laboratory of Water Environment Simulation, School of Environment, Beijing Normal University, Beijing 100875, China
}

Correspondence should be addressed to Xiangzheng Deng; dengxz.ccap@gmail.com

Received 22 August 2013; Accepted 12 November 2013

Academic Editor: Burak Güneralp

Copyright (C) 2013 Xiangzheng Deng et al. This is an open access article distributed under the Creative Commons Attribution License, which permits unrestricted use, distribution, and reproduction in any medium, provided the original work is properly cited.

\begin{abstract}
A framework of land use change dynamics (LUCD) model compatible with regional climate models (RCMs) is introduced in this paper. The LUCD model can be subdivided into three modules, namely, economic module, vegetation change module, and agentbased module. The economic module is capable of estimating the demand of land use changes in economic activities maximizing economic utility. A computable general equilibrium (CGE) modeling framework is introduced and an approach to introduce land as a production factor into the economic module is proposed. The vegetation change module provides the probability of vegetation change driven by climate change. The agroecological zone (AEZ) model is supposed to be the optimal option for constructing the vegetation change module. The agent-based module identifies whether the land use change demand and vegetation change can be realized and provides the land use change simulation results which are the underlying surfaces needed by RCM. By importing the RCMs' simulation results of climate change and providing the simulation results of land use change for RCMs, the LUCD model would be compatible with RCMs. The coupled simulation system composed of LUCD and RCMs can be very effective in simulating the land surface processes and their changing patterns.
\end{abstract}

\section{Introduction}

There are two primary factors that contribute to climate change: land use change and greenhouse gas emission $[1,2]$. Land use change, which has been found to affect climate change in both biogeochemical and biogeophysical ways, is fundamentally important for the researches of regional climate change [3]. In regional climate modeling, land use data are applied as underlying surfaces and definitively determine the simulation results of regional climate [4]. Many simulation experiments have proven that the simulation results of RCMs are sensitive to underlying land use and land cover changes (LUCC) $[5,6]$. While the interaction between land use change and climate change has been fully realized, most RCMs introduce LUCC data exogenously $[7,8]$. Always, they apply the LUCC data of one year of history as underlying surfaces and keep them constant ignoring the interaction between LUCC and climate variations. This paper provides a framework of land use change dynamics (LUCD) model compatible with RCMs to introduce parameterized LUCC into regional climate change modeling endogenously. Several suggested models are introduced and some specific parameter processing approaches are explained in detail. This modeling framework helps to enhance the understanding of the coupling mechanism of land use system and climatic system and strengthen the simulation capability of land system.

Land system is geographically complex, which is composed of natural factors, human land-use activities, and other impact factors [9-11]. Land use change simulation is a prediction of when, where, why, and how land use pattern changes $[12,13]$. However, studies on land use change processes are often challenged by the complex and unexpected human activities and natural constraints. Land use change emerges from the interactions among various components of the coupled 
human-landscape system and feeds back to the subsequent development of these interactions [14]. Most land use change simulation models simulate successional pattern change of land use under the macrobackground of the regional population growth, economic development, social progress, changes in the natural environment, and other facts $[15,16]$. On the whole, the land use change simulation models can be broadly divided into three major categories: empirical statistical model, agent-based model (ABM), and raster neighborhood relationship based model [17].

There are abundant empirical statistical models applied to land use change simulation. A typical example is the Conversion of land use and its effect at small regional extent (CLUES) model whose application in land use change simulation is currently in the ascendant [18-20]. The CLUE-S model is constructed to simulate land use change and its effects on environment at meso/microscale. It has the capability of synchronously simulating the changes of multiple types and introduces the dynamic driving factors (such as population and economic growth) to improve the simulation accuracy. Since the 1990s, along with the rapid development of complexity sci ence, ABM began to be applied to land use change research [21]. The agent-based models of land use and land cover (ABM/LUCC) were specially discussed by LUCC report number 6 , in which the development prospect of ABM in land use change simulation is highly valued [22]. An ABM model mainly identifies the linkage between agents and environment by describing the interaction and affiliation of independent agents [23]. By combining ABM and cellular automata (CA) model, the simulation of land use change is characterized by multiscale and becomes more effective in multiobjective decision making. Semboloni et al. [24] established a multiagent system with the residents, industry practitioners, service practitioners, and developers as the main agents to simulate the land use change in urban areas. Zhang et al. [25] built an ABM to simulate the impacts of the climate changes on the regional land use changes and agents' economic benefits in the Three-River Headwaters Region of China. It is found that the agents would get more wealth under the scenario without climate changes in the long term, even though the total income is lower than that under the scenario with climate changes. As a representative of raster neighborhood relationship based model, CA model is widely used in land use change simulation, especially urban expansion $[26,27]$. Syphard et al. [28] analyzed the distinction of LUCC caused by urban expansion in areas with different slope with the CA model. One of the superiority of the CA model in land use change simulation is that it supports visualization of the simulation process. The structure of the CA model makes it difficult considering the impacts of land use policies.

In this study, we developed an LUCD model compatible with RCMs to describe the interdependencies and feedback mechanisms between social economics, ecosystem environment, and irrational decision-making process. The LUCD model describes a combined and complex system composed of social economic, ecosystem components, and decision-making process and consequences. It provides a consistent and comprehensive framework of land use change modeling and emphasis on how the models work together. By introducing agroecological zone (AEZ) based on the simulation results of RCMs, the LUCD model is compatible with RCMs and constitutes an iterative simulation system of LUCC and climate changes.

\section{Land Use Change Dynamics (LUCD) Model}

2.1. Model Structure. The LUCD model can be subdivided into three modules, namely, economic module, vegetation change module, and agent-based module. The economic modulcalculates the area demand for all land use types in economic activities maximizing economic utility of land uses. The vegetation change module provides the probability of vegetation change driven by climate changes. And the agentbased module identifies whether the land use demand and vegetation change can be realized and provides the land use change simulation results which are the underlying surfaces needed by RCM. To feed the LUCD model results into RCMs, the land use system applied to the LUCD model should be consistent with the underlying surfaces used in RCMs (Figure 1). By iteratively using the output of one model as the input of another, the LUCD model is compatible with RCMs. In Figure 1, the dotted lines show the data transmission between the LUCD model and RCMs, while the solid lines stand for the flow of information in the LUCD model. The LUCD model provides the simulation results of land use change for RCMs as underlying surface data; then RCMs can simulate the climate change resulted from the land use change. The results of climate change simulated by RCMs are further imported into the LUCD model and affect land use change.

The economic module estimates the land use change demand driven by human activity. The current condition of land uses is introduced in this module as one of the limitations of economic activity as well as land use decisions. The equilibrium of markets determines the commodity supply and in turn influences the land use demand. Combining the land use demand, the limited amount of land, and the current land use status, the land use change demand is obtained. The vegetation change module describes the possible vegetation change driven by climate change. The AEZ is the key concept that links the climate change and vegetation change and helps to couple human activity with climate change. The climate change leads to change of AEZs which determines the growth of vegetation [29, 30]. Consequently, the climate change affects not only the evolution of natural vegetation but also the human activities including planting and breeding. By overlying the AEZs on the current vegetation pattern, the suitability of vegetation change can be evaluated. The agentbased module describes the procedure of land use decision coupled with the land use change demand and vegetation change suitability using the agent-based simulation technology. This module identifies whether or not the theoretical land use change demand and the possible vegetation change estimated by the economic module and the vegetation change module can be realized. The output of this module, land use change, is the underlying surfaces that needed by RCMs. By embedding the LUCD in RCMs, an iterative simulation system of land use change and climate change is constructed (Figure 1). 


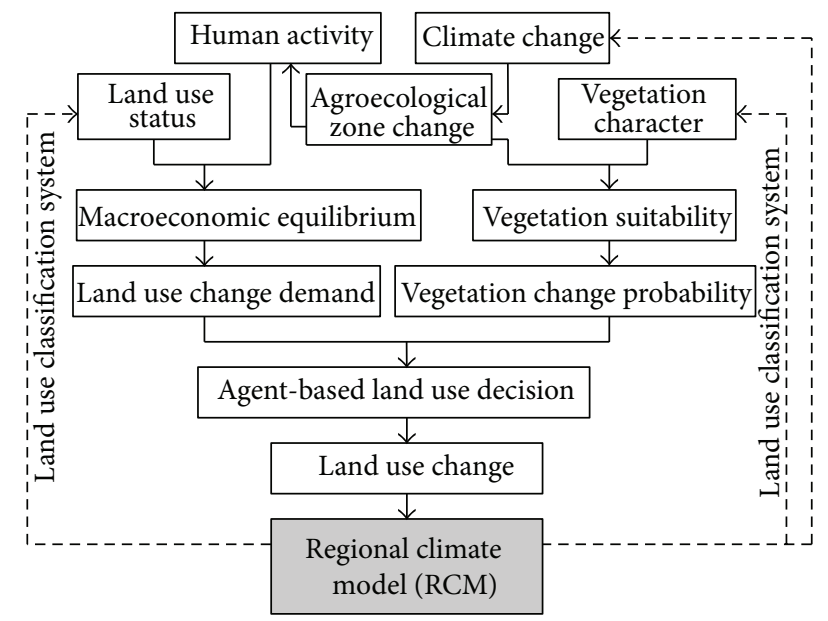

FIGURE 1: Framework of feeding LUCC model results into RCMs simulation.

2.2. Economic Module. The economic module should provide a comprehensive macroeconomic framework to describe market-oriented economies. Computable general equilibrium (CGE) models are suggested to be appropriate for such a macroeconomic framework [31]. For convenient application, the way that induces land into the economic module under a CGE modeling framework is proposed as well in this study (Figure 2). Land is one of the three primary factors input in commodity production. And there are five components: producers, households, government, trade, and markets in CGE model [32]. Producers decide demand of inputs including primary factors of land, labor and capital, and supply of outputs (commodities) to maximize their profits. Households decide demand of commodities and supply of their endowments of labor and capital to maximize their economic utility. Government imposes taxes and expends them in public consumption and savings. The savings of government and households transform into investment according to reserve requirements, which is also an important component in demand. And we employ the small-country assumption that the study area is too small to affect prices in international markets. Thus, import and export prices which this country faces are given for it in foreign currency terms. The demand and supply of commodities and primary factors are equilibrated in markets by price adjustment. With this module, we can compute land uses in various equilibria to simulate what will happen in the future.

Though CGE models are good at describing the quantities and prices variation as others, we do not introduce land prices but land area in the economic module. This is because the land prices vary along with not only time but also location, productivity, and so forth. And as a macroeconomic model, CGE model does not support a diverse prices modeling framework. Thus, we summarize land uses in economic development as follows:

$$
Y_{i, e}=b_{i, e} \prod_{h} F_{h, i, e}^{\beta_{h, i e}} \prod_{l} A e c_{l, i, e}^{\mathcal{G}_{l, i, e}}
$$

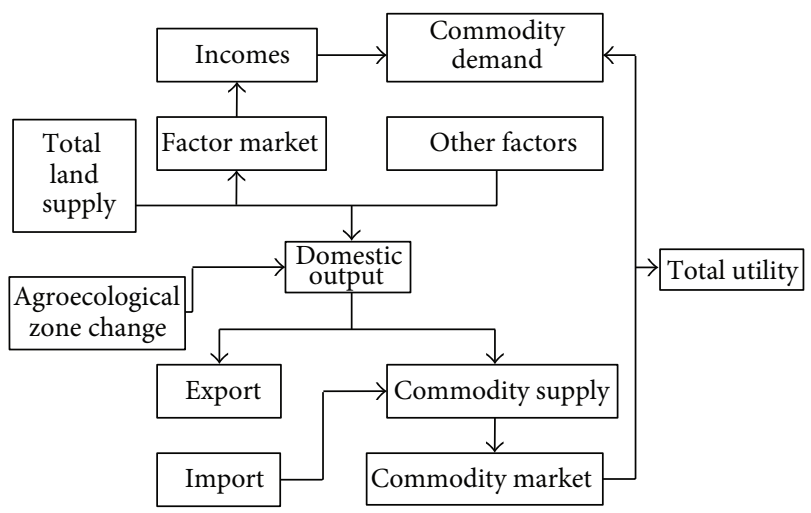

FIGURE 2: Overview flow chart of economic module applying a CGE modeling framework.

$$
\operatorname{Aec}_{l, i, e}=\frac{\zeta_{l, i, e} Y_{i, e}}{b_{i, e}},
$$

where $i$ is the index of commodities; $e$ is the index of AEZs; $l$ is the index of land use type; $h$ is the index of primary factors (labor and capital); $Y_{i, e}$ is the value added of the $i$ th firm in the $e$ th AEZ; $A e c_{l, i, e}$ is the input area of the $l$ th land use type for $i$ th commodity production in the eth AEZ; $F_{h, i, e}$ is the input of the $h$ th factor by the $i$ th firm in the $e$ th AEZ; $b_{i, e}$ is the scaling parameter in production function, also called total factor productivity (TFP); $\zeta_{l, i, e}$ is the share parameter in production functions; and $\beta_{h, i, e}$ is the share parameter in production functions. Considering that the value added is proportional to the input land area under the certain technique condition and primary factors input, the input area of each land use type is calculated by (2).

The input land area of each type of land use per unit of each commodity output is inversely correlated with primary factors input besides TFP. Consequently, the share parameter, $\zeta_{l, i, e}$, is determined by the input of the $h$ th factor by the $i$ th firm in the $e$ th AEZ, $F_{h, i, e}$ :

$$
\zeta_{l, i, e}=f\left(F_{\text {labor }, i, e}, F_{\text {capital }, i, e}\right) .
$$

The area demand of lands input in commodity production is determined by the economic system, because the economic links in the comprehensive macroeconomic framework provided by CGE model are tightly connected with each other. Each shock to economic system will influence the area demand of lands input in commodity production. For example, the growth in the rate of direct tax will lead to an increase in government revenues and a decrease in household income. Then, the structure differences of investments and consumptions between government and household determine the change of commodity demand structure. Under the marketclearing condition, the commodity production and supply structure should be altered. And finally, the area demand of lands input in commodity production will change.

As most of the economic models, the economic module assumes that the ultimate purpose of economic development is to increase the economic utility of household. Household's 
economic utility is dependent on the amount of consumption of commodity, which are purchased from producers:

$$
U e c=\prod_{i} X p_{i}^{\chi_{i}}
$$

where $U e c$ is the economic utility; $X p_{i}$ is the amount of consumption of the $i$ th commodity; and $\chi_{i}$ is the share parameter in the economic utility function.

The economic utility is indirectly restrained by the area of land used for economic development. In reality, the earnings from endowments of land are the component household's income which is the constraint of household consumption. And the input of land in production by producer determines the output and supply of commodity. Nevertheless, we only consider the constraint function of land in production in this module because the earnings from the endowment of land are not included when accounting income constraints. The economic development can be summarized as the following optimization problem:

$$
\begin{array}{ll}
\underset{\left\{X p_{i}\right\}}{\operatorname{maximize}} & U e c=\prod_{i} X p_{i}^{\chi_{i}} \\
\text { subject to } & \text { Tland }=\sum_{e} \sum_{l} \sum_{i} A_{i} e c_{l, i, e},
\end{array}
$$

where Tland is the total land area which is exogenously defined. Equation (4) shows the objective function of economic utility to be maximized, and (5) is a total land area constraint equation meaning that total land areas used for commodity production must be equal to the total land area used in economic activity on the left-hand side of the equation. The simulated land use change demand at regional scale can be allocated to grids by using DLS (dynamics of land systems) model, CLUE-S model, or CA models [33-36], and so forth.

2.3. Vegetation Change Module. The vegetation change module assesses the growth suitability of specific vegetation and provides the possibility of vegetation change. There are many models including dynamic global vegetation model $[37,38]$, Holdridge life zone model [39], and AEZ model [40] that can be used to describe the vegetation change driven by climate change. In this study, we propose AEZ model as the optimal option because it is naturally correlated with AEZs facilitating the coupling of economic module and vegetation change module. We also illustrate how to estimate the possibility of vegetation change using AEZ model. The AEZ model is developed by Food and Agriculture Organization (FAO) of the United Nations with the collaboration of the International Institute for Applied Systems Analysis (IIASA) [41]. Climate, topography, and soil characteristics are three key inputs of the AEZ model. The model can estimate the climate limited vegetation productivity. Assuming that the estimated climate limited productivity of the $v$ th type of vegetation in the pixel $p$ in the $t$ th year is $Y_{v, p, t}$, the possibility of vegetation change of the $v$ th type of vegetation in the pixel $p$ in the $(t+1)$ th year is

$$
P_{v, p, t+1}=\frac{Y_{v, p, t+1}-Y_{v, p, t}}{Y_{v, \max }},
$$

where $Y_{v, \text { max }}$ is the maximum climate limited productivity of the $v$ th type of vegetation and $P_{v, p, t+1}$ is the possibility of vegetation change of the $v$ th type of vegetation in the pixel $p$ in the $(t+1)$ th year.

A positive $P_{v, p, t+1}$ implies that the $v$ th type of vegetation in the pixel $p$ will expand or be more thickly forested $(t+1)$ th year, while a negative $P_{v, p, t+1}$ means that the $v$ th type of vegetation in the pixel $p$ will be inclined to degrade in the in the $(t+1)$ th year. The possibility of vegetation change provides the comparison criterion of specific vegetation change of different pixels in different times. When comparing the superiority of different vegetation in the specific pixel and time, a superiority index, $S_{v, u, p, t}$, is proposed:

$$
S_{v, u, p, t+1}=\frac{Y_{v, p, t+1}-Y_{v, p, t}}{Y_{u, p, t+1}-Y_{u, p, t}},
$$

where $S_{v, u, p, t+1}$ is the superiority index of the $v$ th type of vegetation compared with the $u$ th type of vegetation in the pixel $p$ in the $(t+1)$ th year.

The superiority index cannot depict the dominance relations between two types of vegetation by itself. The application of this index should be combined with the possibility of vegetation change. For instance, when $P_{v, p, t+1}$ is positive and $S_{v, u, p, t+1}$ is larger than 1 , the $v$ th type of vegetation is more superior than the $u$ th type of vegetation in the pixel $p$ in the $(t+1)$ th year. A more exact mathematical formula for judging the dominance relations of multiple types of vegetation is proposed in the agent-based module.

2.4. Agent-Based Module. Determination of land use change is partly characterized by nonrationality such as tradition and custom. The agent-based module identifies whether the land use change demand simulated by economic module and the possible vegetation change assessed by vegetation change module can be realized under the background of irrational decisions. Agent-based modeling is able to simulate land use change by measuring the individual behavior and results of land use over time [42]. Take the decision of land use change of a given household for instance. The dissimilarities between a given household $h$ and all defined household groups in the population can be measured:

$$
D_{h, g}=\sum_{s=1}^{s} w_{s}\left[\frac{\left(V_{h, s}-\bar{V}_{g, s}\right)^{2}}{\left|V_{h, s}+\bar{V}_{g, s}\right|}\right],
$$

where $D_{h, g}$ is the distance from household $h(h=1,2, \ldots, H)$ to the household group $g(g=1,2, \ldots, G) ; V_{h, s}$ is the value of variable $s(s=1,2, \ldots, S)$ representing the character of household $h ; \bar{V}_{g, s}$ is the average value of variable $s$ of households in household group $g$; $w_{s}$ is the weight coefficient of the variable $s$ in explaining the character of household and household group.

The household $h$ is assigned into the most similar household group and makes the same land use change decision with the household group:

$$
g^{\prime}=\arg \min \left\{D_{h, 1}, D_{h, 2}, \ldots, D_{h, g}, \ldots, D_{h, G}\right\},
$$


where $g^{\prime}$ is the most similar household group to household $h$. By establishing a case database of land use change decision, we can assign each household into one similar enough household group and deduce the land use decision. It helps correct the land use change results simulated of economic module based on ideas of optimization.

For the assessment result of vegetation change module, the agent-based module also provides a criterion to judge which kind of vegetation change will happen in a specific pixel:

$$
\begin{aligned}
& L_{v, p} \\
& = \begin{cases}1, & \text { if for } \forall u \neq v, P_{v, p, t+1}>0, S_{v, u, p, t+1}>1 \text { or } \leq 0 \\
& \text { or } P_{v, p, t+1} \leq 0, S_{v, u, p, t+1}>0 \text { or } \leq 1 \\
0, & \text { if for } \forall u \neq v, P_{v, p, t+1}>0, S_{v, u, p, t+1}>0 \text { or } \leq 1\end{cases} \\
& \text { or } P_{v, p, t+1} \leq 0, S_{v, u, p, t+1}>1 \text { or } \leq 0
\end{aligned}
$$

where $L_{v, p}=1$ denotes that the $v$ th type of vegetation is the dominant vegetation in the pixel $p$ and $L_{v, p}=0$ denotes that the $v$ th type of vegetation is not the dominant vegetation in the pixel $p$. This criterion defines that, for any other vegetation type $u$, when $P_{v, p, t+1}$ is positive and $S_{v, u, p, t+1}$ is larger than 1 or no larger than 0 , or $P_{v, p, t+1}$ is not positive and $S_{v, u, p, t+1}$ is smaller than 0 or no larger than 1 , the $v$ th type of vegetation is the dominant vegetation in the pixel $p$ in the $(t+1)$ th year; when $P_{v, p, t+1}$ is positive and $S_{v, u, p, t+1}$ is larger than 0 or no larger than 1 , or $P_{v, p, t+1}$ is not positive and $S_{v, u, p, t+1}$ is larger than 1 or no larger than 0 , the $v$ th type of vegetation is not the dominant vegetation in the pixel $p$ in the $(t+1)$ th year.

For a specific pixel, vegetation change will happen as long as the productivity of the new dominant vegetation exceeds that of the original dominant vegetation:

$$
\begin{gathered}
L V_{p, t+1}=v, \quad \text { if for } \forall u \neq v, \quad R Y_{v, p, t+1}>R Y_{u, p, t+1} \\
R Y_{v, p, t+1}=R Y_{v, p, t}+\frac{R Y_{v, p, t}}{R Y_{p, t}} Y_{v, p, t+1} \\
R Y_{p, 0}=\sum_{v} \frac{A_{v, p, 0}}{A_{p}} Y_{v, p, 0}
\end{gathered}
$$

where $L V_{p, t+1}$ denotes the new vegetation type that characterized the pixel $p$ in the $(t+1)$ th year; $R Y_{v, p, t+1}$ is the productivity of the $v$ th type of vegetation in the pixel $p$ in the $(t+$ 1)th year; $R Y_{p, t}$ is the total productivity of all the vegetation in the pixel $p$ in the $t$ th year; $R Y_{p, 0}$ is the total productivity of all the vegetation in the pixel $p$ in the base year; $A_{p}$ is area of pixel; $A_{v, p, 0}$ is area the $v$ th type of vegetation in the pixel $p$ in the base year; and $Y_{v, p, 0}$ is the productivity of the $v$ th type of vegetation in the pixel $p$ in the base year.

\section{Discussion and Conclusions}

In this paper, we introduced the LUCD model which is compatible with RCMs to provide endogenous underlying surface for climate modeling. This model is constituted by economic module, vegetation change module, and agent-based module. The economic module calculates the land use change demand driven by economic activities aiming at maximizing economic utility. The vegetation change module evaluates the probability of vegetation change driven by climate change. These two modules depict the land surface process under the condition of rational decision making and ideal circumstances. To couple the economic module and vegetation change module, the AEZ was introduced in the LUCD model. The agent-based module identifies whether the land use change demand and vegetation change can be realized under the condition of irrational decision making and multiple vegetation competition. By introducing the simulation results of the LUCD model in RCM and applying the simulation results of RCM in the LUCD model, a coupled simulation system of land surface system simulation can be established.

In addition to the modeling framework, several suggested models were introduced and some specific parameter processing approaches were explained in detail for the constitution of the LUCD model. For the economic module, a CGE modeling framework and the difference between land and other production factors in CGE model were introduced. The effects of climate change on human activities were also taken into consideration by establishing production function for each AEZ. The AEZ model was suggested for the vegetation change module and two indexes (possibility of vegetation change and superiority index) were supposed to determine the climate-induced vegetation change. For the agent-based module, an example of land use change decision making and the criterion of vegetation change was provided.

The LUCD model offers a framework integrating human activities and climate change, rational and irrational decision makings, and macro- and microdynamic models into the land use change. The model is spatially explicit and has a good empirical applicability by integrating natural vegetation change and land use change. By embedding the LUCD model results into RCMs' climate simulation, regional land use change and climate change can be iteratively simulated, which will undoubtedly enhance the understanding of land surface system dynamics.

To ensure that the output on LUCC of LUCD model easily feeds into RCMs' simulation, the classification system of LUCC in the LUCD model should be comparable with that of underlying surface data needed by RCMs. The classification system determines the choice of driving factors that affect land use change, vegetation change, and decision making processes in the LUCD model. In other words, the modeling approaches of three modules of the LUCD model should be accordant with specific RCM, which is one of the major reasons by which we keep the LUCC classification flexible in the LUCD model. The proposed LUCC classification system, by default in the LUCD model, is compatible for most of RCMs. And the specific parameter processing approaches provided in this study can also serve as valuable examples even if a new modeling approach is used in module construction in the LUCD model.

Both the LUCD and RCMs are grid based, while the grid scale RCMs used are always much more rough for land use 
change modeling. Though there are more and more researches applying RCM based on high resolution grid data, the difference in grid scale is still kept as one of the major challenges in coupling the LUCD model and RCMs [43-46]. We suggest introduction of subgrid to solve the grid scale issue. The LUCC simulation in the LUCD model can be based on a high resolution grid data and the simulation of climate change in RCMs can be implemented at a low resolution grid scale.

Besides the grid scale issue, the temporal scale difference is the problem that hinders the seamlessly embedding of the LUCD model into RCM. The simulation of RCM should be hourly while that of the LUCD might be yearly based at least. The alteration of underlying surface data in RCMs will certainly result in a sudden variation of simulation results. Consequently, the analysis of hourly climate data exported by RCMs will make little sense. Therefore, we suggest the simulation results of RCM be reconciled to monthly or yearly for analysis. And it is apparent that the simulation results of RCMs should be reconciled to yearly for the purpose of input into the LUCD model.

\section{Acknowledgments}

This research was supported by National Key Programme for Developing Basic Science in China (no. 2010CB950900), the Key Project funded by the Chinese Academy of Sciences (no. KZZD-EW-08), and the National Department Public Benefit Research Foundation of the Ministry of Land and Resources of China (no. 201311001-5).

\section{References}

[1] E. Kalnay and M. Cai, "Impact of urbanization and land-use change on climate," Nature, vol. 423, pp. 528-531, 2003.

[2] C. D. Thomas, A. Cameron, R. E. Green et al., "Extinction risk from climate change," Nature, vol. 427, pp. 145-148, 2004.

[3] R. A. Pielke Sr., "Land use and climate change," Science, vol. 310, no. 5754, pp. 1625-1626, 2005.

[4] A. Grell, J. Dudhia, and D. R. Stauffer, "A description of the fifthgeneration Penn State/NCAR mesoscale model (MM5)," NCAR Technical Note, Boulder, Colo, USA, 1994.

[5] J. M. Shepherd, M. Carter, M. Manyin, D. Messen, and S. Burian, "The impact of urbanization on current and future coastal precipitation: a case study for houston," Environment and Planning B, vol. 37, no. 2, pp. 284-304, 2010.

[6] C.-Y. Lin, W.-C. Chen, P.-L. Chang, and Y.-F. Sheng, "Impact of the urban heat island effect on precipitation over a complex geographic environment in Northern Taiwan," Journal of Applied Meteorology and Climatology, vol. 52, no. 3, pp. 570-587, 2011.

[7] Y. Z. Lin, A. P. Liu, E. J. Ma, X. Li, and Q. L. Shi, "Impacts of future urban expansion on regional climate in the Northeast Megalopolis, USA," Advances in Meteorology, vol. 2013, Article ID 362925, 10 pages, 2013.

[8] Y. J. Cai, L. C. Tan, H. Cheng et al., "The variation of summer monsoon precipitation in central China since the last deglaciation," Earth and Planetary Science Letters, vol. 291, no. 1-4, pp. 21-31, 2010.

[9] B. L. Turner II, W. C. Clark, R. W. Kates, J. F. Richards, J. T. Mathews, and W. B. Meyer, The Earth as Transformed by Human
Action: Global and Regional Changes in the Biosphere over the Past 300 Years, Cambridge University Press, Cambridge, UK, 1993.

[10] J. Y. Liu, M. L. Liu, D. F. Zhuang, Z. X. Zhang, and X. Z. Deng, "Study on spatial pattern of land-use change in China during 1995-2000," Science in China D, vol. 46, no. 4, pp. 373-384, 2003.

[11] GLP, "GLP science plan andimplementation strategy," IGBP Report no. 53/ IHDP Report no. 19, IGBP Secretariat, Stockholm, Sweden, 2005.

[12] X. Z. Deng, Q. O. Jiang, H. B. Su, and F. Wu, "Trace forest conversions in Northeast China with a 1-km area percentage data model," Journal of Applied Remote Sensing, vol. 4, no. 1, Article ID 041893, pp. 1-13, 2010.

[13] C. H. Zhao, X. Z. Deng, Y. W. Yuan, H. M. Yan, and H. Liang, "Prediction of drought risk based on the WRF model in Yunnan Province of China," Advances in Meteorology, vol. 2013, Article ID 295856, 9 pages, 2013.

[14] Q. B. Le, S. J. Park, P. L. G. Vlek, and A. B. Cremers, "Land-use dynamic simulator (LUDAS): a multi-agent system model for simulating spatio-temporal dynamics of coupled human-landscape system. I. structure and theoretical specification," Ecological Informatics, vol. 3, no. 2, pp. 135-153, 2008.

[15] J. Y. Liu and X. Z. Deng, "Progress of the research methodologies on the temporal and spatial process of LUCC," Chinese Science Bulletin, vol. 55, no. 14, pp. 1354-1362, 2010.

[16] J. Y. Liu and X. Z. Deng, "Impacts and mitigation of climate change on Chinese cities," Current Opinion in Environmental Sustainability, vol. 3, no. 3, pp. 188-192, 2011.

[17] J. Y. Liu, H. Q. Tian, M. L. Liu, D. F. Zhuang, J. M. Melillo, and Z. X. Zhang, "China's changing landscape during the 1990s: large-scale land transformations estimated with satellite data," Geophysical Research Letters, vol. 32, no. 2, pp. 1-5, 2005.

[18] A. Veldkamp and L. O. Fresco, "CLUE: a conceptual model to study the conversion of land use and its effects," Ecological Modelling, vol. 85, no. 2-3, pp. 253-270, 1996.

[19] Z. Q. Duan, F. R. Zhang, and L. M. Miao, "Neighborhood-based method for land-use spatial pattern analysis and its application," Transactions of the Chinese Society of Agricultural Engineering, vol. 22, no. 6, pp. 71-76, 2006.

[20] X. Z. Deng, Q. O. Jiang, J. Y. Zhan, S. J. He, and Y. Z. Lin, “Simulation on the dynamics of forest area changes in Northeast China," Journal of Geographical Sciences, vol. 20, no. 4, pp. 495509, 2010.

[21] T. P. Evans and H. Kelley, "Multi-scale analysis of a household level agent-based model of landcover change," Journal of Environmental Management, vol. 72, no. 1-2, pp. 57-72, 2004.

[22] W. J. McConnell, "Agent-based models of land-use and landcover change," LUCC Report no. 6, 2001.

[23] S. Manson, "Land use in the Southern Yucatán peninsular region of Mexico: scenarios of population and institutional change," Computers, Environment and Urban Systems, vol. 30, no. 3, pp. 230-253, 2006.

[24] F. Semboloni, J. Assfalg, S. Armeni, R. Gianassi, and F. Marsoni, "CityDev, an interactive multi-agents urban model on the web," Computers, Environment and Urban Systems, vol. 28, no. 1-2, pp. 45-64, 2004.

[25] T. Zhang, J. Y. Zhan, J. Huang, R. Yu, and C. C. Shi, "An agentbased reasoning of impacts of regional climate changes on land use changes in the Three-River Headwaters region of China," Advances in Meteorology, vol. 2013, Article ID 248194, 9 pages, 2013. 
[26] M. Batty, Y. C. Xie, and Z. L. Sun, "Modeling urban dynamics through GIS-based cellular automata," Computers, Environment and Urban Systems, vol. 23, no. 3, pp. 205-233, 1999.

[27] J. I. Barredo, M. Kasanko, N. McCormick, and C. Lavalle, "Modelling dynamic spatial processes: simulation of urban future scenarios through cellular automata," Landscape and Urban Planning, vol. 64, no. 3, pp. 145-160, 2003.

[28] A. D. Syphard, K. C. Clarke, and J. Franklin, "Using a cellular automaton model to forecast the effects of urban growth on habitat pattern in Southern California," Ecological Complexity, vol. 2, no. 2, pp. 185-203, 2005.

[29] FAO, Agro-Ecological Zoning Guidelines, vol. 73 of FAO Soils Bulletin, Food and Agriculture Organization of the United Nations, Rome, Italy, 1996.

[30] E. Stehfest, M. Heistermann, J. A. Priess, D. S. Ojima, and J. Alcamo, "Simulation of global crop production with the ecosystem model DayCent," Ecological Modelling, vol. 209, no. 2-4, pp. 203-219, 2007.

[31] X. Z. Deng, H. B. Su, and J. Y. Zhan, "Integration of multiple data sources to simulate the dynamics of land systems," Sensors, vol. 8, no. 2, pp. 620-634, 2008.

[32] X. Z. Deng, F. Yin, Y. Z. Lin, Q. Jin, and R. J. Qu, "Equilibrium analyses on structural changes of land uses in Jiangxi Province," Journal of Food, Agriculture and Environment, vol. 10, no. 1, pp. 846-852, 2012.

[33] X. Z. Deng, Q. O. Jiang, J. Y. Zhan, S. J. He, and Y. Z. Lin, "Simulation on the dynamics of forest area changes in Northeast China," Journal of Geographical Sciences, vol. 20, no. 4, pp. 495509, 2010.

[34] P. H. Verburg, W. Soepboer, A. Veldkamp, R. Limpiada, V. Espaldon, and S. S. A. Mastura, "Modeling the spatial dynamics of regional land use: the CLUE-S model," Environmental Management, vol. 30, no. 3, pp. 391-405, 2002.

[35] K. H. Lau and B. H. Kam, "A cellular automata model for urban land-use simulation," Environment and Planning B, vol. 32, no. 2, pp. 247-263, 2005.

[36] D. Li, X. Li, X. P. Liu et al., "GPU-CA model for large-scale landuse change simulation," Chinese Science Bulletin, vol. 57, no. 19, pp. 2442-2452, 2012.

[37] S. Scheiter, L. Langan, and S. I. Higgins, "Next-generation dynamic global vegetation models: learning from community ecology," The New Phytologist, vol. 198, no. 3, pp. 957-969, 2013.

[38] F. I. Woodward and M. R. Lomas, "Vegetation dynamics-Simulating responses to climatic change," Biological Reviews of the Cambridge Philosophical Society, vol. 79, no. 3, pp. 643-670, 2004.

[39] T. X. Yue, J. Y. Liu, S. E. Jørgensen, Z. Q. Gao, S. H. Zhang, and X. Z. Deng, "Changes of Holdridge life zone diversity in all of China over half a century," Ecological Modelling, vol. 144, no. 2-3, pp. 153-162, 2001.

[40] Q. L. Shi, Y. Z. Lin, E. P. Zhang, H. M. Yan, and J. Y. Zhan, "Impacts of cultivated land reclamation on the climate and grain production in Northeast China in the future 30 Years," Advances in Meteorology, vol. 2013, Article ID 853098, 8 pages, 2013.

[41] J. Schmidhuber and F. N. Tubiello, "Global food security under climate change," Proceedings of the National Academy of Sciences of the United States of America, vol. 104, no. 50, pp. 19703-19708, 2007.

[42] P. Deadman, D. Robinson, E. Moran, and E. Brondizio, "Colonist household decisionmaking and land-use change in the Amazon Rainforest: an agent-based simulation," Environment and Planning B, vol. 31, no. 5, pp. 693-709, 2004.
[43] S. R. Gaffin, C. Rosenzweig, R. Khanbilvardi et al., "Variations in New York city's urban heat island strength over time and space," Theoretical and Applied Climatology, vol. 94, no. 1-2, pp. 1-11, 2008.

[44] J. M. Liu and X. Z. Deng, "Influence of different land use on urban microenvironment in Beijing City, China," Journal of Food, Agriculture and Environment, vol. 9, no. 3-4, pp. 1005-1011, 2011.

[45] L. Tian, J. Q. Chen, and S. X. Yu, "How has Shenzhen been heated up during the rapid urban build-up process?" Landscape and Urban Planning, vol. 115, pp. 18-29, 2013.

[46] J. Y. Liu, Z. X. Zhang, X. L. Xu et al., "Spatial patterns and driving forces of land use change in China during the early 21st century," Journal of Geographical Sciences, vol. 20, no. 4, pp. 483-494, 2010. 

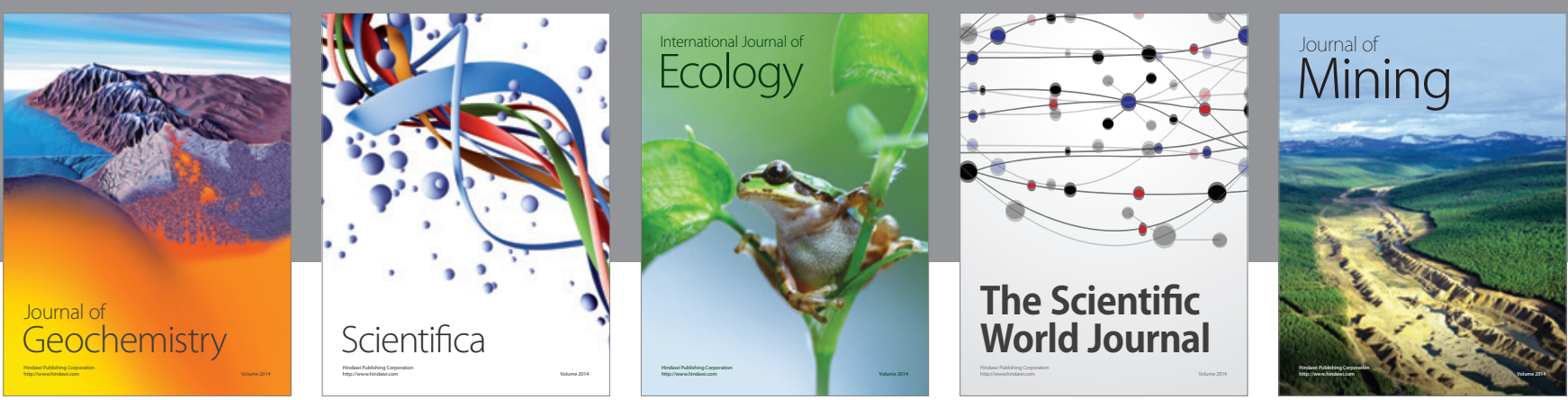

The Scientific World Journal
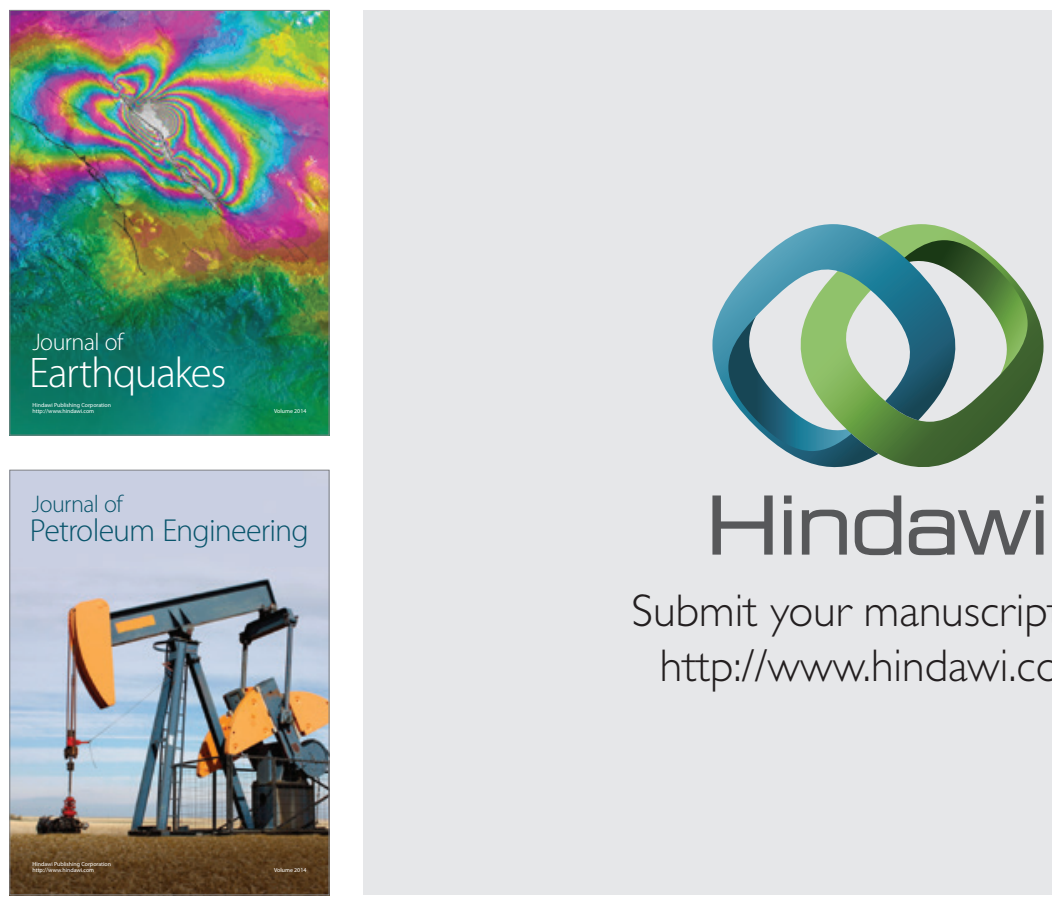

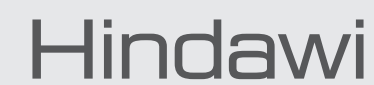

Submit your manuscripts at

http://www.hindawi.com
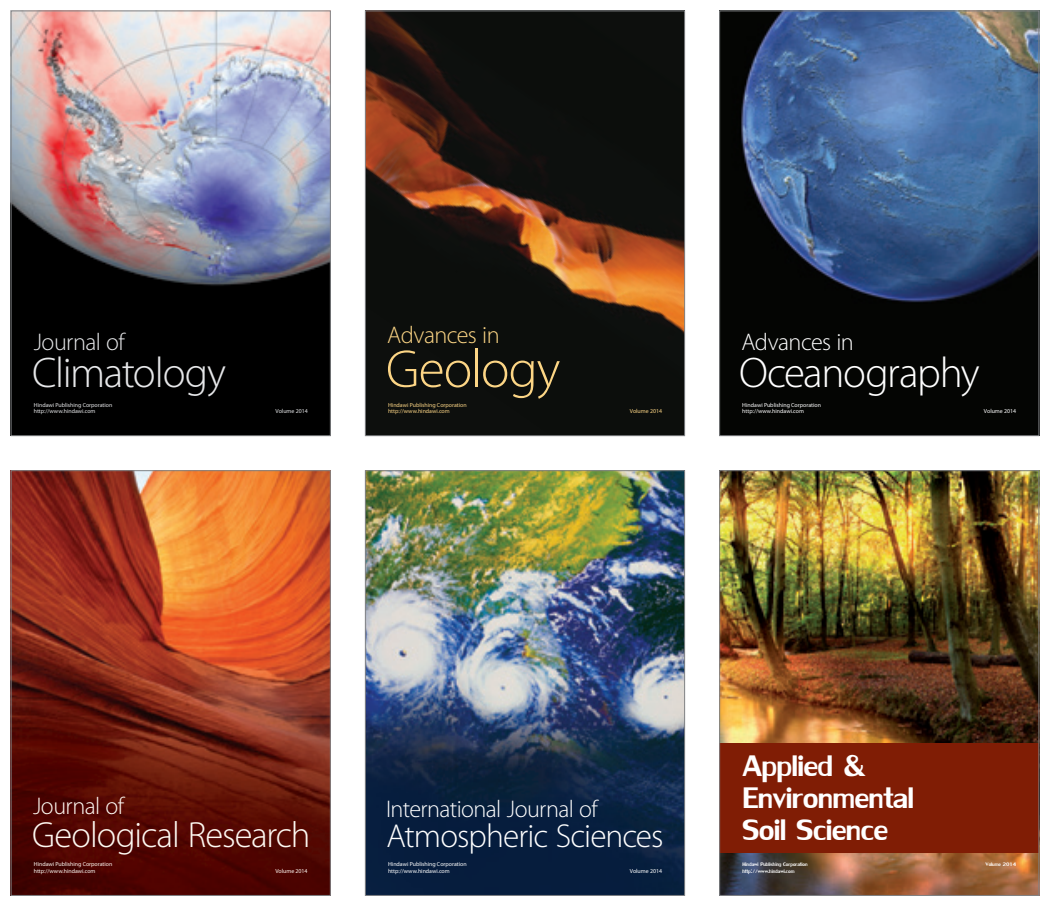
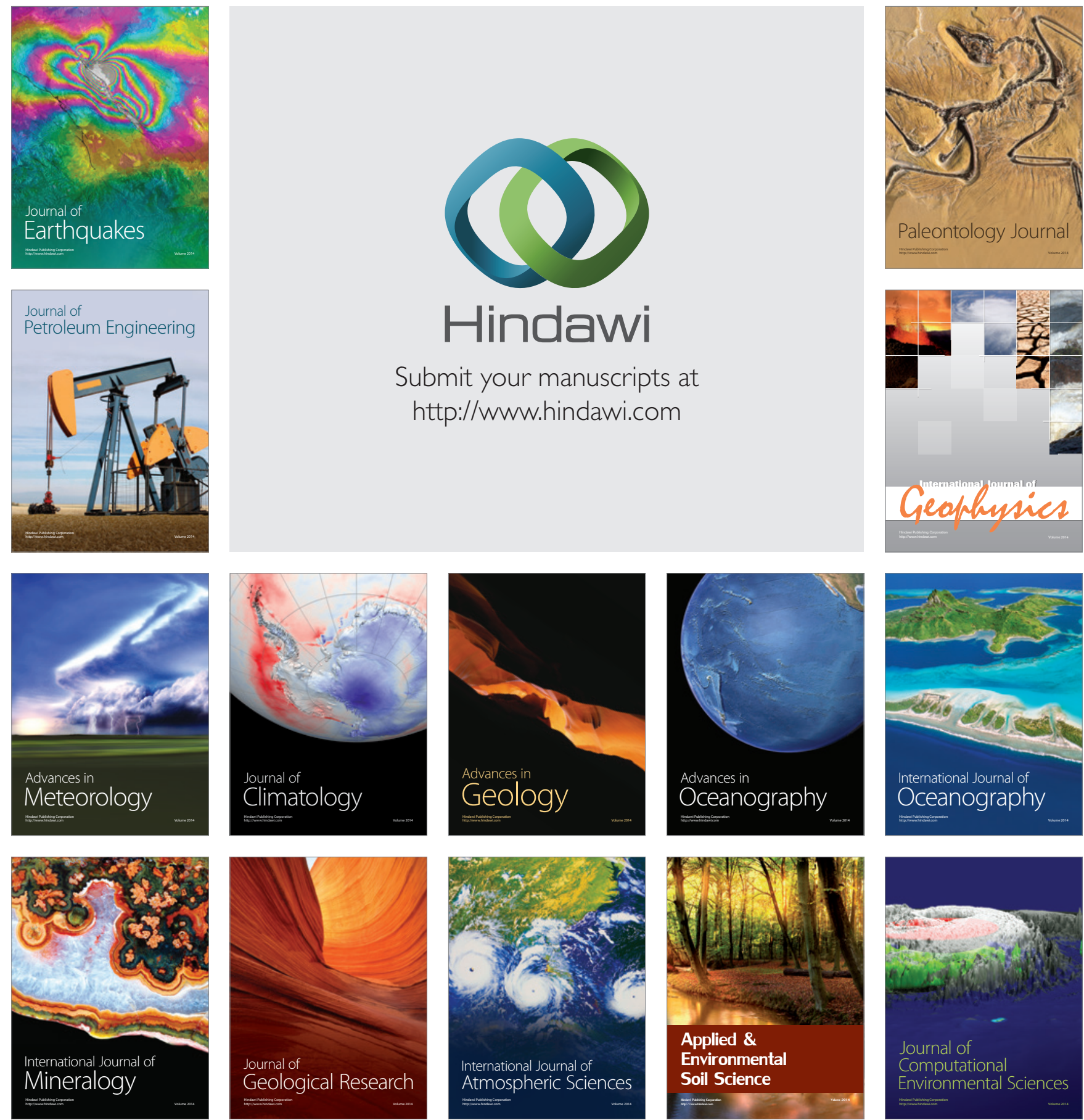